\title{
Temperature-induced configuration changes in hydrogel-coated coils and their relevance in embolization procedures
}

\author{
Ruben Lopez Benitez ${ }^{1 *}$, Tomas Reyes del Castillo ${ }^{1}$, Levent Kara², Joachim Kettenbach ${ }^{3}$ and Justus Roos ${ }^{1}$
}

\begin{abstract}
Background: The present study attempted to demonstrate how the configuration of hydrogel-coated coils is influenced by different temperature exposures.

Thirty detachable hydrogel-coated coils were evaluated in an in vitro water immersion test under five different temperature ranges $\left(22.6^{\circ} \mathrm{C}, 37^{\circ} \mathrm{C}, 40-50^{\circ} \mathrm{C}, 50-60^{\circ} \mathrm{C}\right.$, and $\left.60-70^{\circ} \mathrm{C}\right)$. The configuration changes were classified (configuration I, configuration II, and configuration III) according to the curling that occurred during 30 min of immersion. Configuration stability of five Hydrogel-coated coils was also evaluated in a two-step temperature immersion test.
\end{abstract}

Results: All hydrogel-coated coils showed some configuration changes during water immersion. However, a logarithmic transformation of the time and temperature data showed a significant $(p<0.05)$ negative linear correlation between time and temperature for all coil configurations (configuration I: $R=0.97$, configuration II: $R=$ 0.98 , configuration III: $R=0.97$ ). The time needed to reach configuration III (complete coiling) was $160.4 \pm 41.9 \mathrm{~s}$ at $37.5^{\circ} \mathrm{C}$ (range: $100-205 \mathrm{~s}$ ), $45.7 \pm 22.2 \mathrm{~s}$ at $47.5^{\circ} \mathrm{C}$ (range: $23-70 \mathrm{~s}$ ), $20.2 \pm 7.2 \mathrm{~s}$ at $57.5^{\circ} \mathrm{C}$ (range: $14-32 \mathrm{~s}$ ), and $10.3 \pm$ $2.4 \mathrm{~s}$ at $67.5^{\circ} \mathrm{C}$ (range: $7-13 \mathrm{~s}$ ).

Conclusions: Temperatures above $55^{\circ} \mathrm{C}$ induced immediate configurational changes in the hydro-coated coils, achieving complete curling within less than $30 \mathrm{~s}$. Temperatures near $36^{\circ} \mathrm{C}$ (normal body temperature) require more time to reach optimal coil curling (configuration III). The optimization of HydroCoil preparation can reduce interventional procedural time and improve clinical results.

Keywords: Interventional radiology, Embolization procedures, Hydro-coated coils, Temperature-induced configuration, Water immersion, Coil optimization

\section{Background}

Vessel embolization using a coil technique is a challenging procedure that requires technical skills and a detailed knowledge of the properties of the materials employed. In order to achieve complete embolization of the target vessel and avoid complications, embolization materials should be selected according to their special

\footnotetext{
*Correspondence: ruben.lopezbenitez@luks.ch

'Department of Radiology and Nuclear Medicine, Luzerner Kantonsspital, 6000 Luzern, Switzerland

Full list of author information is available at the end of the article
}

features, taking into account either the clinical indication and/or the vascular bed anatomy (Orron et al., 2018).

Coils are one of the most frequently used materials for vascular occlusion. On a basic level, coils are metal filaments made of platinum, cobalt-chrome, or nitinol (Schelhorn et al., 2014; Pech et al., 2009). Recently, HydroCoils ${ }^{\bullet}$ (MicroVention Inc., Tustin, CA) have been introduced as a coil system designed to improve coilpacking density. This is achieved by a layer of hydrogel acrylic polymer surrounding a platinum core, which increases in thickness and diameter when in contact with liquid or blood (Fohlen et al., 2018).

\section{Springer Open}

(c) The Author(s). 2020 Open Access This article is licensed under a Creative Commons Attribution 4.0 International License, which permits use, sharing, adaptation, distribution and reproduction in any medium or format, as long as you give appropriate credit to the original author(s) and the source, provide a link to the Creative Commons licence, and indicate if changes were made. The images or other third party material in this article are included in the article's Creative Commons licence, unless indicated otherwise in a credit line to the material. If material is not included in the article's Creative Commons licence and your intended use is not permitted by statutory regulation or exceeds the permitted use, you will need to obtain permission directly from the copyright holder. To view a copy of this licence, visit http://creativecommons.org/licenses/by/4.0/. 
An efficient HydroCoil configuration improves the embolization effect. An optimized configuration can save expensive materials and unnecessary coiling of the extended vascular segments (Lopez-Benitez et al., 2013). In the present in-vitro study, we attempted to precisely define how HydroCoil configuration can be influenced by exposure to different water temperatures.

\section{Materials}

Thirty detachable HydroCoils were used in the present study. All were tested in an open-fluid thermostatic system consisting of the following parts: a polyurethane immersion chamber, a thermostatic system with a maximal temperature variation range of $0.5^{\circ} \mathrm{C}$ (Voltkraft ${ }^{\mathrm{GmbH}}$, Hirschau, Germany), and a digital thermometer with a measurement range of $-199.9^{\circ} \mathrm{C}$ to $+850.0^{\circ} \mathrm{C}$ (GMH 3750, Greisinger Electronic ${ }^{\mathrm{GmbH}}$, Regenstauf, Germany) calibrated according to the Swiss certification (Cert. 112, 954; Fig. 1).

The immersion chamber was filled with $500 \mathrm{ml}$ of sterile $0.9 \% \mathrm{NaCl}$ solution with 2000 units of heparin (Liquemin, Drossapharm ${ }^{\mathrm{AG}}$, Basel, $\left.\mathrm{CH}\right)$, simulating the exact conditions of the fluids used in conventional angiographic procedures.

Water temperature was regulated and maintained using an external thermostat (Voltkraft ${ }^{\mathrm{GmbH}}$, Hirschau, Germany), thus ensuring qualitative and reproducible conditions. All measurements were recorded for subsequent analysis using a high-definition camera (SonyHDV, Sony, Japan) and recorded on a DN-300a 250GB data video unit (Datavideo ${ }^{\circ}$, Utrecht, Holland). The timing of configuration changes was measured using a digital chronometer (T3-precision, Suunto ${ }^{\mathrm{Tx}}$, Vantaa, Finland).

\section{Methodology}

The experimental design consisted of two parts: a onestep temperature immersion test and a two-step temperature immersion test.

\section{One-step temperature immersion test}

The time measurements were chronometrically registered from the time at which the hydrogel-coated coils were manually immersed into the fluid chamber (at the selected temperature range) until the time at which one of the configurations was achieved and no further changes were observed. In accordance with the study design, we performed the experiments under five different temperature ranges: $22.6{ }^{\circ} \mathrm{C}$ (room temperature), $37^{\circ} \mathrm{C}$ (body temperature), $40-50{ }^{\circ} \mathrm{C}, 50-60^{\circ} \mathrm{C}$, and $60-70^{\circ} \mathrm{C}$.

Twenty-five $(n=25)$ HydroCoils $\left(0.035^{\prime \prime}\right.$ wire diameter, 8-mm loop, 60-mm length) were analyzed with five in each temperature group. Each configuration change was classified as one of three morphologies (Fig. 1):

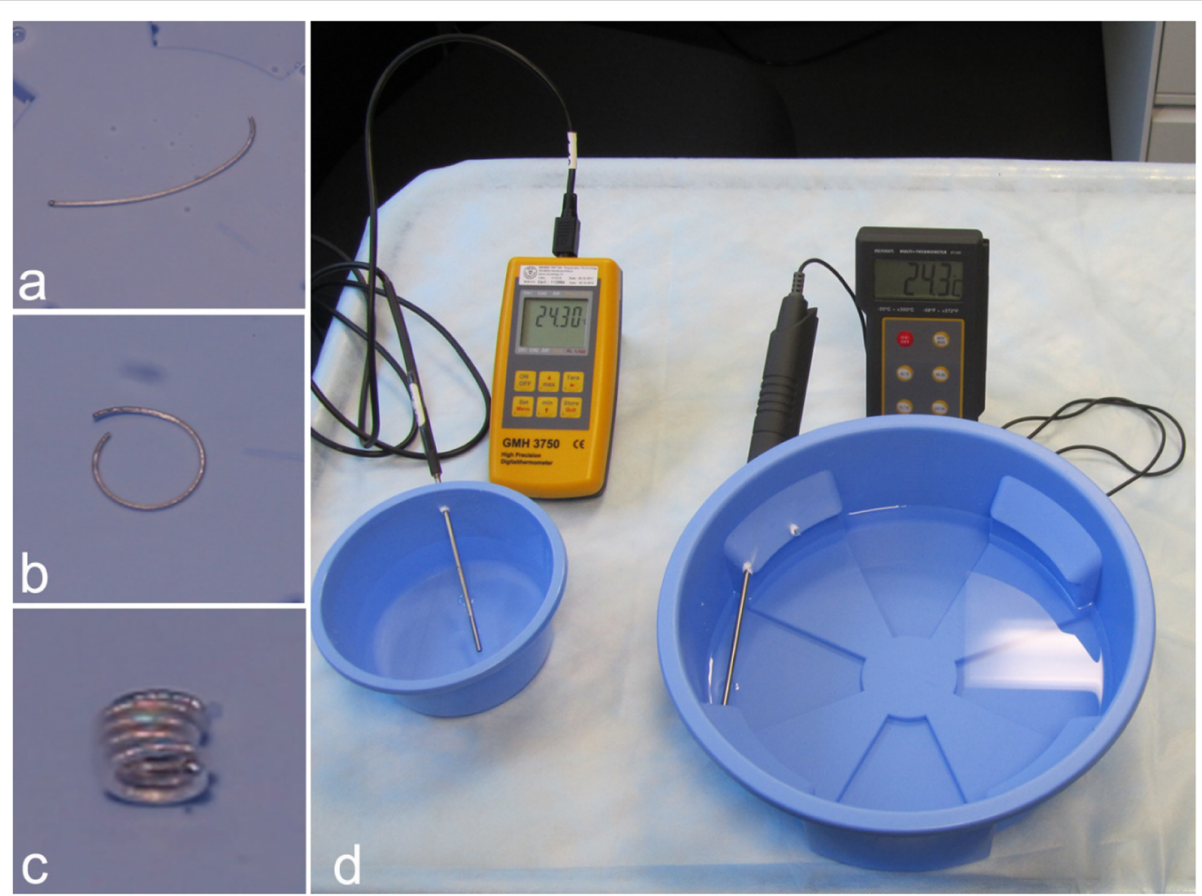

Fig. 1 Classification of HydroCoil configurational changes: Configuration I, minimal curvature of the HydroCoil without reaching a first loop (a); Configuration II, first complete loop without complete curling of the HydroCoil (b); Configuration III, complete HydroCoil curling (c). d shows two different experimental open-fluid immersion chambers with their respective digital thermometer systems (the external thermostat and chronometers are not shown) 
Configuration I: Minimal curvature of the hydro-coated coil without reaching a first loop.

Configuration II: First complete loop without complete curling of the hydro-coated coil.

Configuration III: Complete/final hydro-coated coil curling.

Time measurements were stopped under one of the following conditions: 1) when the investigators (two observers: RLB and TR) confirmed that a complete and stable configuration of the coil (Configuration III) had been achieved or 2) at $30 \mathrm{~min}$ in cases of incomplete coil configuration. Values were measured and registered in minutes, seconds, and milliseconds.

\section{Two-step temperature immersion test}

In the second part of the study, five $(n=5)$ detachable hydrogel-coated coils were analyzed to assess the configuration memory of the material. The detachable hydrocoated coils were first immersed in a $70{ }^{\circ} \mathrm{C}$ water bath. Once a completely coiled shape was reached (Configuration III), the coil was retracted into its plastic sheath and pulled out of the immersion chamber. After $10 \mathrm{sec}-$ onds at room temperature (approximately $26^{\circ} \mathrm{C}$ ), the hydrogel-coated coil was immersed in a $37^{\circ} \mathrm{C}$ bath and released from its sheath. The time period until the HydroCoil reached complete coiling was measured. The purpose of this test was to assess whether a HydroCoil that was completely configured once would be able to instantly regain that configuration after being released from its sheath at physiologic temperatures, simulating a clinical environment (i.e., the preparation of the HydroCoil outside of the patient and subsequent placement in the target vessel).

\section{Statistical analysis}

All data were analyzed and evaluated using Stata software version 12.1 (Stata Corp. LP, College Station, TX, USA). The data values are expressed as means \pm standard deviations.

\section{Results}

The measurements of time until certain coil configurations were reached in relation to the solution temperature are summarized in Table 1 and Fig. 2 (note the use of double logarithmic scales). In all temperature categories, all the HydroCoils showed some form of configuration change after immersion in water (Fig. 3). All five HydroCoils reached Configuration I at room temperature, whereas only three HydroCoils reached Configurations II and III. The average time needed to reach a particular configuration was $327 \pm 38 \mathrm{~s}$ for Configuration I (range: $300-376 \mathrm{~s}$ ), $408 \pm 49 \mathrm{~s}$ for Configuration II (range: 367-462 s), and $820 \pm 336 \mathrm{~s}$ for
Table 1 HydroCoil configuration according to temperature increments

\begin{tabular}{llll}
\hline Temperature & $\begin{array}{l}\text { Configuration I } \\
\text { Average [sec] } \\
\text { (data range) }\end{array}$ & $\begin{array}{l}\text { Configuration II } \\
\text { Average [sec] } \\
\text { (data range) }\end{array}$ & $\begin{array}{l}\text { Configuration III } \\
\text { Average [sec] } \\
\text { (data range) }\end{array}$ \\
\hline $22.5^{\circ} \mathrm{C}$ & $327(300-376)$ & $408(367-462)$ & $820(433-1026)$ \\
$37.5^{\circ} \mathrm{C}$ & $17.3(10.4-24.8)$ & $37.5(18.5-51.4)$ & $160(100-205)$ \\
$47.5^{\circ} \mathrm{C}$ & $5.7(3.4-9.6)$ & $12.2(6.4-19.8)$ & $45.8(22.9-70.0)$ \\
$57.5^{\circ} \mathrm{C}$ & $2.3(1.5-3.0)$ & $5.0(3.5-7.0)$ & $20.2(14.0-32.0)$ \\
$67.5^{\circ} \mathrm{C}$ & $1.5(1.0-2.0)$ & $2.3(1.0-3.5)$ & $10.3(7.0-13.0)$ \\
\hline
\end{tabular}

Measurements of time until a certain coil configuration was reached in relation to one of five different temperature groups. Data are summarized in averages and ranges

Configuration III (range: 433-1026 s). At temperatures above $37^{\circ} \mathrm{C}$, all HydroCoils reached Configuration III within $30 \mathrm{~min}$. The individual times needed to reach Configuration III (complete coiling) were $160.4 \pm 41.9 \mathrm{~s}$ at $37.5^{\circ} \mathrm{C}$ (range: $100-205 \mathrm{~s}$ ), $45.7 \pm 22.2 \mathrm{~s}$ at $47.5^{\circ} \mathrm{C}$ (range: $23-70 \mathrm{~s}$ ), $20.2 \pm 7.2 \mathrm{~s}$ at $57.5^{\circ} \mathrm{C}$ (range: $14-32 \mathrm{~s}$ ), and $10.3 \pm 2.4 \mathrm{~s}$ at $67.5^{\circ} \mathrm{C}$ (range: $7-13 \mathrm{~s}$ ).

As Fig. 2 shows, there was a strong relationship between the temperature of the water bath and the time needed to reach a certain coil configuration. After a log transformation of time and temperature, the data showed a significant $(p<0.05)$ negative linear correlation between time and temperature for all coil configurations (Configuration I: $R=0.97$, Configuration II: $R=0.98$, Configuration III: $R=0.97$ ).

For the two-step temperature immersion test, the temperature of the water bath was intentionally higher (above $70^{\circ} \mathrm{C}$ ) in order to achieve Configuration III in a short period of time $(4.1 \pm 0.9 \mathrm{~s}$; range: $3.2-5.4 \mathrm{~s})$. After the HydroCoil had retracted into its sheath and remained at room temperature $\left(26^{\circ} \mathrm{C}\right)$ for 10 seconds, it was reimmersed in the $37.5^{\circ} \mathrm{C}$ water bath. All the examined HydroCoils immediately regained the fully coiled configuration when reimmersed in the $37^{\circ} \mathrm{C}$ bath. Therefore, no time measurements were possible.

All the HydroCoils were kept in a case at room temperature without humidity exposure and macroscopically analyzed 3 months after the experimental assay. There were no reoccurrences of configurational shape changes. The HydroCoils that had acquired Configurations I, II, and III after the experiment retained the same configurations (Fig. 4).

\section{Discussion}

In the present study, we evaluated how a HydroCoil configuration is influenced when immersed in a water bath at different temperatures.

The timing of HydroCoil configuration is influenced by the temperature of a sterile water bath outside the patient, and the coil materials have been verified to have 


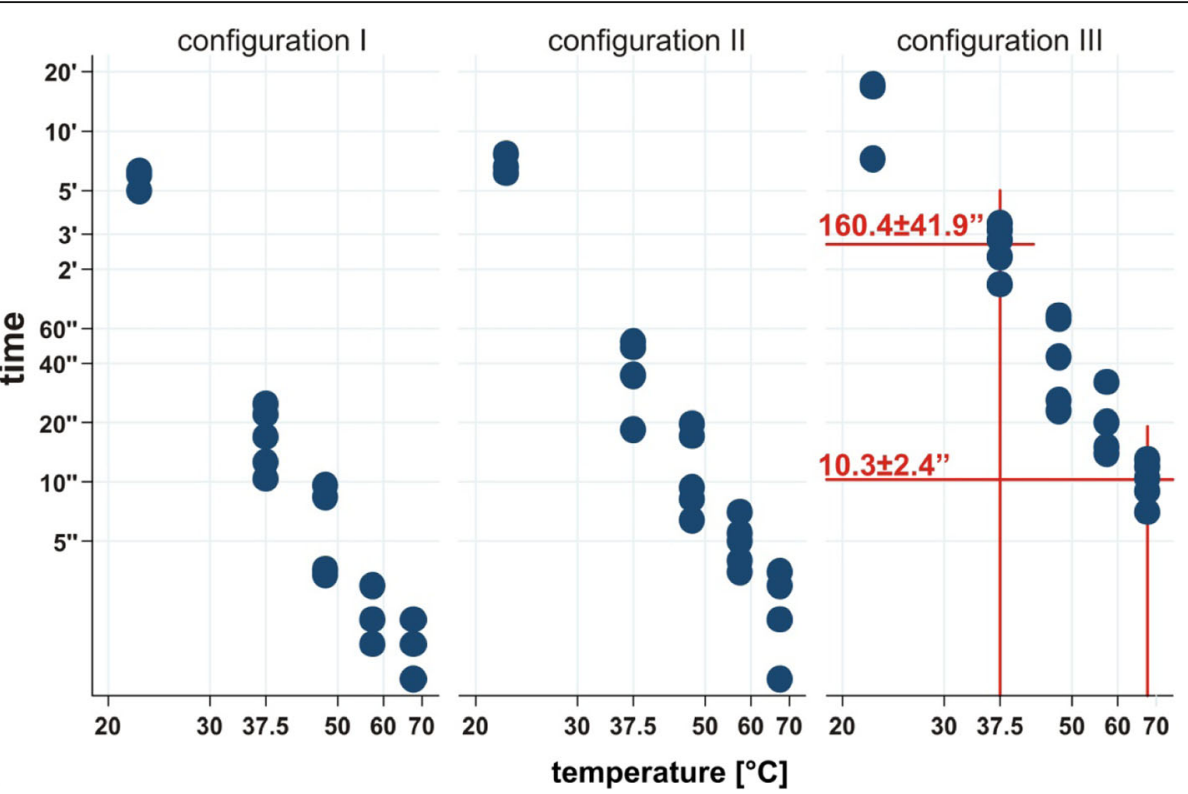

Fig. 2 Temperature-induced HydroCoil configuration changes. Scatter plots of time needed to reach a specific coil configuration as a function of temperature. Note the use of a double logarithmic scale. The time points at which Configuration III was achieved at $37^{\circ} \mathrm{C}$ and $70^{\circ} \mathrm{C}$ are highlighted in red

a memory effect. This enables one to apply these materials more efficiently (i.e., through coil packing and the use of less material) and to achieve a more targeted embolization, thus avoiding the embolization of extended vascular segments.

There are two clinical situations in which the modification of temperature applied to a HydroCoil can influence embolization performance. The first example is the use of detachable HydroCoils in the setting of protective embolization in selective internal radioembolization therapy (SIRT) procedures (Lopez-Benitez et al., 2013).
In this case, the preparation of the HydroCoil by brief immersion in a sterile water bath at $55-70{ }^{\circ} \mathrm{C}$ allows for a fast preconfiguration and compact design of the HydroCoil, which allow for very accurate deployment in the proximal part of the gastroduodenal artery (GDA; Fig. 4).

Another example is the embolization of narrow vessels that are not accessible even with a microcatheter. In such cases, other embolic materials (e.g., particles or glues) usually increase the risk of complications, such as non-target embolization or tissue necrosis (Abdalkader

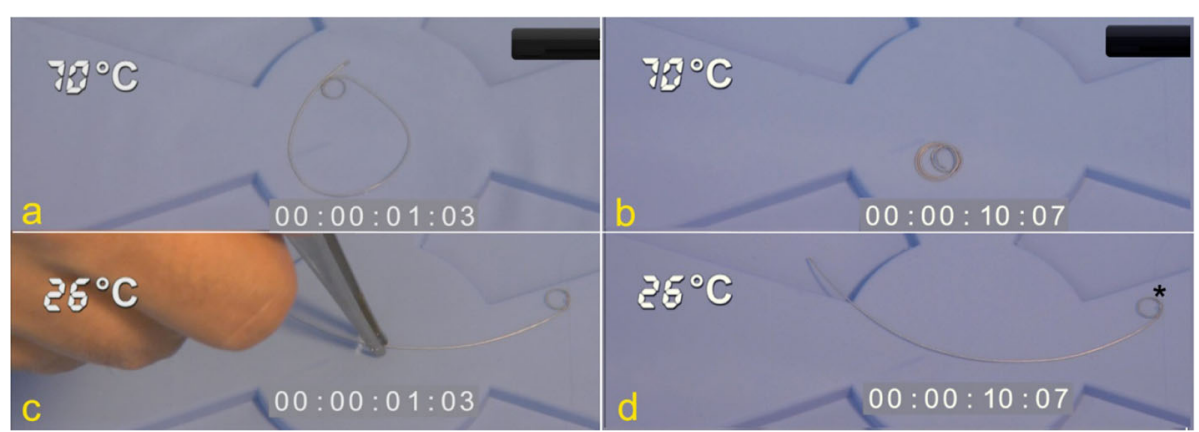

Fig. 3 HydroCoil configuration changes according to different water temperatures. a shows a first loop configuration (Configuration II) after only 01:03 s in a $70^{\circ} \mathrm{C}$ water immersion. b shows complete coiling (Configuration III) after only 10:07 s in a $70^{\circ} \mathrm{C}$ water immersion. c shows a HydroCoil during the first second after immersion at $26^{\circ} \mathrm{C}$; only a discrete strain (Configuration I) was observed after 10:07 s in a $26^{\circ} \mathrm{C}$ water bath immersion (d); this HydroCoil remained without configurational changes even after several minutes (not shown). NOTE: All HydroCoils are designed with a preformed first loop at the tip of the filament (black asterisk); in normal conditions, this first loop facilitates the initial binding of the HydroCoil. This first loop should not be misinterpreted as a temperature-induced coil binding, which actually comprises the totality of the HydroCoil filament 


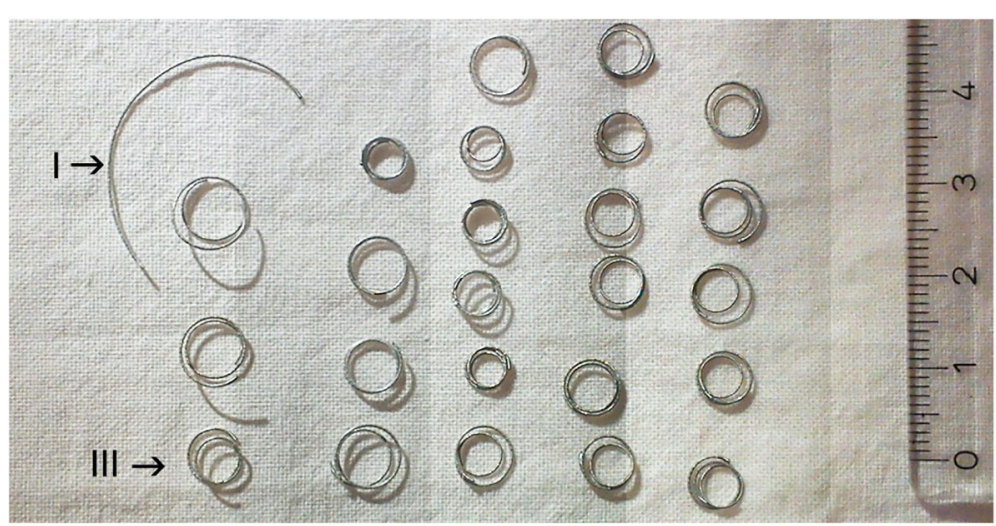

Fig. 4 Differently configured HydroCoils (Configurations I and III) three months after the experimental assay. In all the cases, the morphology obtained during the experiment remained unmodified. Configuration II is not illustrated

et al., 2020; Kim et al., 2017; Lopez-Benitez et al., 2007). In our department, these narrow vessels are successfully embolized using a non-configured detachable HydroCoil, taking advantage of the filament-like configuration to navigate through the vessel; the occlusion results from the secondary intravascular expansion of the hydrogel coating. Even if the desired embolization of a vascular segment is located several centimeters away from the tip of the microcatheter, embolization is possible because the HydroCoil is able to navigate as a guide wire through the vascular bed until the desired vessel segment is reached. In this clinical setting, an early configuration of the HydroCoil must be avoided to allow sufficient time to place the coil. Therefore, the preparation of the HydroCoil by immersion in a sterile water bath at room temperature $\left(\approx 26^{\circ} \mathrm{C}\right)$ will not significantly induce changes in its configuration; this makes it possible to push the HydroCoil as a guide wire into distal segments (Fig. 5).

Interestingly, when a patient is embolized in a real clinical situation, the elapsed time during the entire passage of the HydroCoil through the microcatheter to the desired embolization area could theoretically induce recooling in the previously prepared HydroCoil that had been immersed in a warm bath $\left(>55^{\circ} \mathrm{C}\right)$. It is conceivable that this change in temperature (from $>55^{\circ} \mathrm{C}$ to $37^{\circ} \mathrm{C}$, body temperature) should result in a loss of the previously induced curling capability.

The results of the two-step immersion test revealed that the HydroCoils had excellent thermic memory, as

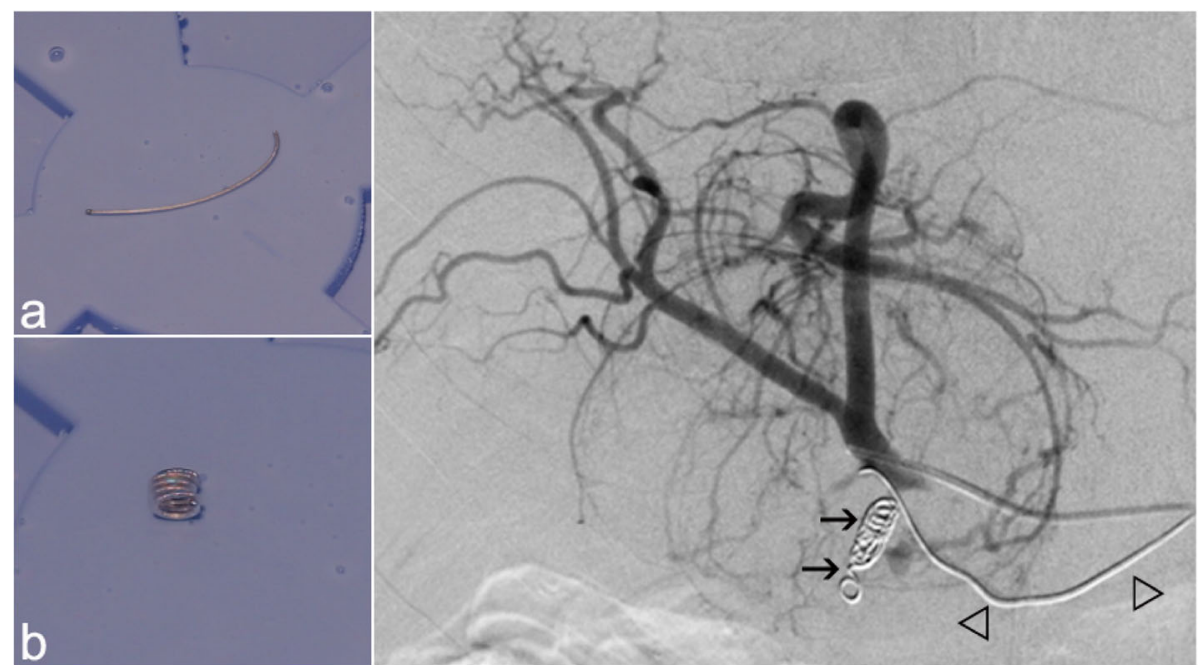

Fig. 5 Correlation of two different HydroCoil configurations in a patient prepared for a selective internal radioembolization procedure. The filament-like HydroCoil configuration (a) allows access to narrow vessels, such as the right gastric artery, in a retrograde fashion (arrowheads) using the expandable capabilities of the HydroCoil to induce vascular occlusion. After preparation at $55-70{ }^{\circ} \mathrm{C}$ (b), the compact configuration of a curled HydroCoil is useful for the proximal occlusion of the gastroduodenal artery (arrows) to avoid particle reflux during the radioembolization procedure 
all of them recovered their complete configurations after a cooling cycle of 10 seconds at room temperature $\left(\approx 26^{\circ} \mathrm{C}\right)$ and reimmersion in a $37^{\circ} \mathrm{C}$ water bath. After the experiments were finished, all the HydroCoils were kept for 3 months at room temperature. In all cases, the final configurations (Configurations 0 to III) obtained during the experiment did not change (Fig. 5). In other words, once a HydroCoil is preheated and has taken on a curled configuration, it will not return to a straight form even if it is cooled down to room temperature.

In many institutions, the use of steam is common when the induction of configurational changes in materials is required (e.g., coil preshaping and catheter shaping). For the purposes of this study, steam was not used to increase the temperatures of the HydroCoils mainly because it is not possible to maintain a controlled, sustained baseline temperature under experimental conditions (this requires exact values). In liquid water, temperature can be regulated and maintained as needed for long periods of time with the use of a thermostat, ensuring qualitative and reproducible conditions.

In our institution, we perform more than 250 embolization procedures every year. HydroCoils have been used in many of these procedures, depending on the clinical indication and the anatomical conditions of each particular case. We have observed that the total number of coil devices needed for embolization and the time required for complete vascular occlusion have reduced significantly since we started modifying the temperature before HydroCoil deployment. Moreover, the acceptable handling of this material and the lower late recanalization rates offered by their expandable capabilities make HydroCoils optimally valuable embolization materials (Maleux et al., 2013; Brinjikji et al., 2015; Ferral, 2015).

\section{Conclusion}

Temperatures above $55{ }^{\circ} \mathrm{C}$ induce immediate configuration changes in HydroCoils, achieving complete coiling in less than 30 s. Optimization during HydroCoil preparation can reduce total interventional procedure times. Moreover, knowledge of thermically induced configurational changes can enable the use of this material in different clinical settings.

\section{Abbreviations \\ SIRT: Selective internal radioembolization therapy; GDA: Gastroduodenal artery}

\section{Acknowledgments}

We are grateful for support by the Ludwig-Boltzman-Institute of Vienna and to Mary McAllister, John Hopkins University Hospital, Baltimore MD, for her assistance.

\section{Authors' contributions}

RLB was the main author of the manuscript. TR and KL were major contributors in writing the manuscript and performed the laboratory investigation. $\mathrm{KJ}$ and JR substantively revised it. All authors read and approved the final manuscript.

\section{Funding}

This laboratory investigation was not supported by any funding.

\section{Availability of data and materials}

Not applicable.

\section{Ethics approval and consent to participate}

All procedures performed in studies involving human participants were in accordance with the ethical standards of the institutional and/or national research committee and with the 1964 Helsinki declaration and its later amendments or comparable ethical standards. For this type of study consent for publication is not required.

\section{Consent for publication}

Not applicable.

\section{Competing interests}

The authors declare that they have no conflict of interest.

\section{Author details}

${ }^{1}$ Department of Radiology and Nuclear Medicine, Luzerner Kantonsspital, 6000 Luzern, Switzerland. ${ }^{2}$ Stadtspital Triemli Zürich, Institute of Radiology and Nuclear Medicine, 8063 Zurich, Switzerland. ${ }^{3}$ Zentralröntgeninstitut für Diagnostik, Interventionelle Radiologie und Nuklearmedizin, Landesklinikum Wiener Neustadt, 2700 Wiener Neustadt, Austria.

Received: 29 October 2020 Accepted: 1 December 2020

Published online: 10 December 2020

\section{References}

Abdalkader M, Piotin M, Chen M et al (2020) Coil migration during or after endovascular coiling of cerebral aneurysms. J Neurointerv Surg 12(5):505511. https://doi.org/10.1136/neurintsurg-2019-015278

Brinjiki W, White PM, Nahser $\mathrm{H}$ et al (2015) HydroCoils reduce recurrence rates in recently ruptured medium-sized intracranial aneurysms: a subgroup analysis of the HELPS trial. AJNR Am J Neuroradiol 36(6):1136-1141. https://doi.org/ 10.3174/ajnr.A4266

Ferral H (2015) Hydrogel-coated coils: product description and clinical applications. Semin Intervent Radiol 32(4):343-348. https://doi.org/10.1055/s0035-1564809

Fohlen A, Namur J, Ghegediban $\mathrm{H}$ et al (2018) Peripheral embolization using hydrogel-coated coils versus fibered coils: short-term results in an animal model. Cardiovasc Intervent Radiol 41(2):305-312. https://doi.org/10.1007/ s00270-017-1834-7

Kim PH, Tsauo J, Shin JH, Yun SC (2017) Transcatheter arterial embolization of gastrointestinal bleeding with n-Butyl cyanoacrylate: a systematic review and meta-analysis of safety and efficacy. J Vasc Interv Radiol 28(4):522-531.e5. https://doi.org/10.1016/j.jvir.2016.12.1220

Lopez-Benitez R, Hallscheidt P, Kratochwil C et al (2013) Protective embolization of the gastroduodenal artery with a one-HydroCoil technique in radioembolization procedures. Cardiovasc Intervent Radiol 36:105-110. https://doi.org/10.1007/s00270-012-0361-9

Lopez-Benitez R, Radeleff BA, Barragan-Campos HM et al (2007) Acute pancreatitis after embolization of liver tumors: frequency and associated risk factors. Pancreatology 7(1):53-62

Maleux G, Deroose C, Fieuws S et al (2013) Prospective comparison of hydrogelcoated microcoils versus fibered platinum microcoils in the prophylactic embolization of the gastroduodenal artery before yttrium-90 radioembolization. J Vasc Interv Radiol 24(6):797-804. https://doi.org/10.1016/ j.jvir.2013.01.503

Orron DE, Bloom Al, Neeman Z (2018) The role of transcatheter arterial embolization in the management of nonvariceal upper gastrointestinal bleeding. Gastrointest Endosc Clin N Am 28(3):331-349. https://doi.org/10. 1016/j.giec.2018.02.006 
Pech M, Kraetsch A, Wieners G et al (2009) Embolization of the gastroduodenal artery before selective internal radiotherapy: a prospectively randomized trial comparing platinum-fibered microcoils with the Amplatzer Vascular Plug II. Cardiovasc Intervent Radiol 32(3):455-461

Schelhorn J, Theysohn J, Ertle J et al (2014) Selective internal radiation therapy of hepatic tumours: is coiling of the gastroduodenal artery always beneficial? Clin Radiol 69(5):e216-e222. https://doi.org/10.1016/j.crad.2013.12.015

\section{Publisher's Note}

Springer Nature remains neutral with regard to jurisdictional claims in published maps and institutional affiliations.

Submit your manuscript to a SpringerOpen ${ }^{\mathcal{O}}$ journal and benefit from:

- Convenient online submission

- Rigorous peer review

- Open access: articles freely available online

- High visibility within the field

- Retaining the copyright to your article

Submit your next manuscript at $\boldsymbol{\nabla}$ springeropen.com 